\title{
Multidimensional capillary gas chromatography for the monitoring of individual non-methane hydrocarbons in air
}

\author{
M. Veillerot, N. Locoge, J.C. Galloo and R. Guillermo \\ Département Chimie et Environnement, École des Mines de Douai, 941 rue Charles Bourseul, 59508 Douai Cedex, France
}

\begin{abstract}
Mainly of anthropogenic origin, volatile organic compounds (VOCs) are now well known to represent air pollutants of first priority, because of their harmful direct and indirect impacts on human health. So, a permanent and continuously monitoring of individual VOC in the atmosphere and especially in urban air becomes more and more required. In this paper, the ability of the multidimensional gas chromatography to constitute an alternative possibility in the monitoring of individual non-methane hydrocarbons (NMHC) in the atmosphere is demonstrated. The principle of the method as well as of the sampling and analytical system are described. Results obtained from a 2 years monitoring experiment in different areas in Douai are also reported.
\end{abstract}

$\mathrm{V}$ olatile organic compounds (VOC) are now commonly regarded as first priority air pollutants considering the various problems their presence in the atmosphere causes [1]. In particular, VOC have worrying impacts on public health by playing a direct and indirect role in the exposure of the population to air toxic compounds. Some of them like benzene or 1,3-butadiene are actually known or suspected to have carcinogenic and mutagenic properties for human beings. Then VOC, with nitrogen oxides, take a significant part in the complex photochemical mechanisms leading to the formation in near-the-ground levels of the atmosphere of secondary harmful compounds such as ozone or peroxyacylnitrates. These effects are of major importance in urban areas where elevated concentrations and high population densities are found simultaneously. In these places, VOC are mainly composed of non-methane hydrocarbons (NMHC) with carbon atom number up to twelve $\left(\mathrm{C}_{12}\right)$ and have principally an anthropogenic origin, from road transport, industrial and domestic activities. So, there is a strong demand for a permanent and continuously monitoring of individual VOC in the atmosphere and especially for NMHC in urban air, measurements which could be useful in particular for:

- carrying out the epidemiological studies for the assessment of the exposure of the population to toxic components,

- verifying the efficiency of emission control policies on levels in ambient air,

- supplying data for the validation of photochemical models simulating the physico-chemical processes occurring in the atmosphere.
At present, the available methods for the individual measurement of NMHC in air are developed in specialised laboratories mainly for research purposes and are based exclusively upon non-continuous gas chromatography techniques. They generally use a two step procedure considering first a concentrating sampling stage followed by the chromatographic separation of the components on high resolution capillary columns [2]. Single column approach is usually chosen for the separation of NMHC, and two kinds of stationary phases have been ordinarily used: either Alumina PLOT column [3,4] or polydimethylsiloxane apolar one $[5,6]$. The former is suitable for separation of light $\mathrm{C}_{2}$ hydrocarbons, but strongly retains less volatile components, limiting the analysis up to $\mathrm{C}_{8}$. On the contrary, the latter is unable to resolve light components, even considering subambient cooling of the oven with cryogenic fluid, but provides correct separation for highest boiling fraction of NMHC in air [7].

An alternative possibility is multidimensional gas chromatography, which considers a two combined column approach, and gives simultaneously a correct resolution for all the components of interest, in the lowest analysis time.

\section{Multidimensional gas chromatography}

Multidimensional gas chromatography (MDGC) is a very powerful chromatographic tool for both favouring complete separation of very complex mixtures and reducing the time of analysis. This technique is based on the time-commanded connection, following predetermined experimental procedures, of different analytical columns with complementary separation abilities [8]. At chosen moments, insufficiently resolved fractions coming from a first analytical column can be selectively switched to another more effective one. The resolution finally obtained by MDGC, and without increasing the analysis duration, is always better than single column techniques, even considering the best commercially available ones [9]. The simplest example of MDGC, known as "heart-cutting" chromatography, uses two columns, as illustrated in the schematic diagram given in figure 1.

A first column, often a preparative packed one, is connected to a second analytical column, of different polarity, by a switching device. This one directs the flow from the pre-column to either a detector (in control mode), or the analytical column (in heart-cutting mode). A deactivated fused silica column plays simultaneously the role of a transfer line for the detector 1 and of a flow restriction to equilibrate the carrier gas pressures inside the switching device. 


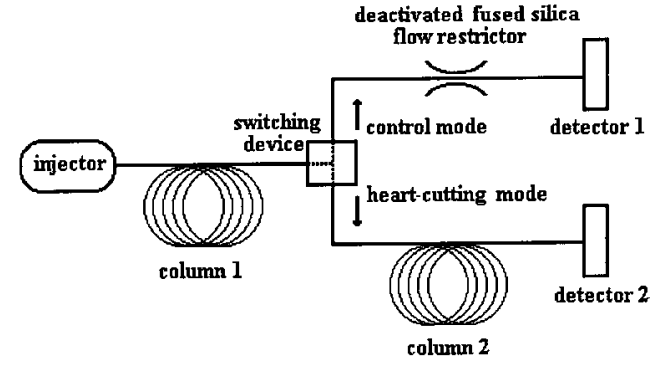

Figure 1. Schematic flow diagram for heart-cutting gas chromatography, adapted from [8].

Such dual column systems are used for laboratory research application or for industrial process control in very different fields, like wine quality control [10], fuels characterisation [8], exhaust gases analyses [11], and recently for the determination of volatile organic in air $[2,12]$. In our laboratory, heart-cutting switching facilities are installed on different chromatographs for various analysis of organics in the atmosphere or in exhaust gases. In particular, we have developed a specific application that we have been using for more than two years for the hourly monitoring of individual NMHC in urban air.

\section{Analytical system}

\section{Air sampling}

Air sampling is provided by the Perkin Elmer ATD 400 system, in its on-line mode. In this configuration, the sampling and injection operations are fully automated. Air, collected at a constant flow rate regulated by a mass flow controller, is first dried with the help of a permeable Nafion membrane (Perma Pure). In this way, water is removed from the sample and does not interfere with the focusing device and the analytical system [2]. Then, air is directed to a sorbent trap maintained at $-30{ }^{\circ} \mathrm{C}$ by a Peltier cooling system. At this moderately low temperature, the complete trapping of NMHC in the range of $\mathrm{C}_{2}$ to $\mathrm{C}_{10}$, is obtained with the help of a two phase $100 \mathrm{mg}$ mixed sorbent bed, consisting of Carbopack and Carbosieve SIII (both 60/80 mesh from Supelco). A $600 \mathrm{~mL}$ maximum volume of air can be collected without a breakthrough of the trap for the $\mathrm{C}_{2}$ hydrocarbons. At the end of the sampling stage, the cartridge is quickly heated $\left(40{ }^{\circ} \mathrm{C} / \mathrm{s}\right)$ up to $300{ }^{\circ} \mathrm{C}$ and maintained at this temperature during 10 minutes, while it is swept by an inert flow gas circulating in the opposite direction of sampling. The compounds are then desorbed from the trap and injected into the chromatographic system through a heated $\left(200{ }^{\circ} \mathrm{C}\right)$ deactivated fused silica capillary transfer line. In order to ensure a quick injection of the desorbed compounds into the capillary columns, a desorption flow higher than the column carrier gas flow is required, what is practically achieved by a splitter device. A split factor set at 1.5 was experimentally found to be enough for a correct resolution of all eluting peaks.

\section{Chromatographic separation}

The separation of individual NMHC is performed on a Perkin Elmer Autosystem gas chromatograph equipped with a dual column pneumatic switching facility. A schematic flow diagram indicating the switch working is shown in figure 2.

The two capillary columns used for the NMHC separation, a Plot fused silica $\mathrm{Al}_{2} \mathrm{O}_{3} / \mathrm{Na}_{2} \mathrm{SO}_{4}$ (Chrompack, $50 \mathrm{~m} \times$ $0.32 \mathrm{~mm} ; 5.0 \mu \mathrm{m}$ film thickness) and a CP-Sil-5 CB (Chrompack, $50 \mathrm{~m} \times 0.25 \mathrm{~mm} ; 1.0 \mu \mathrm{m}$ film thickness) are initially connected according to the heart-cutting mode. The compounds desorbed from the concentration trap and pushed by the carrier gas (helium) penetrate the CP-Sil column first. The lighter components, weakly retained on this column, are allowed to enter the Plot alumina column where they can be resolved and then detected by the flame ionisation detector number 2 (FID 2). When the heavier components appear to be correctly resolved on the CP-Sil column, the additional carrier gas supply is then switched by the means of the 3port valve and the effluent coming from this column is directed to the FID number 1. From this moment, each column works independently with its own carrier gas and detector. The chromatographic conditions used for the analysis are summarised in table I.

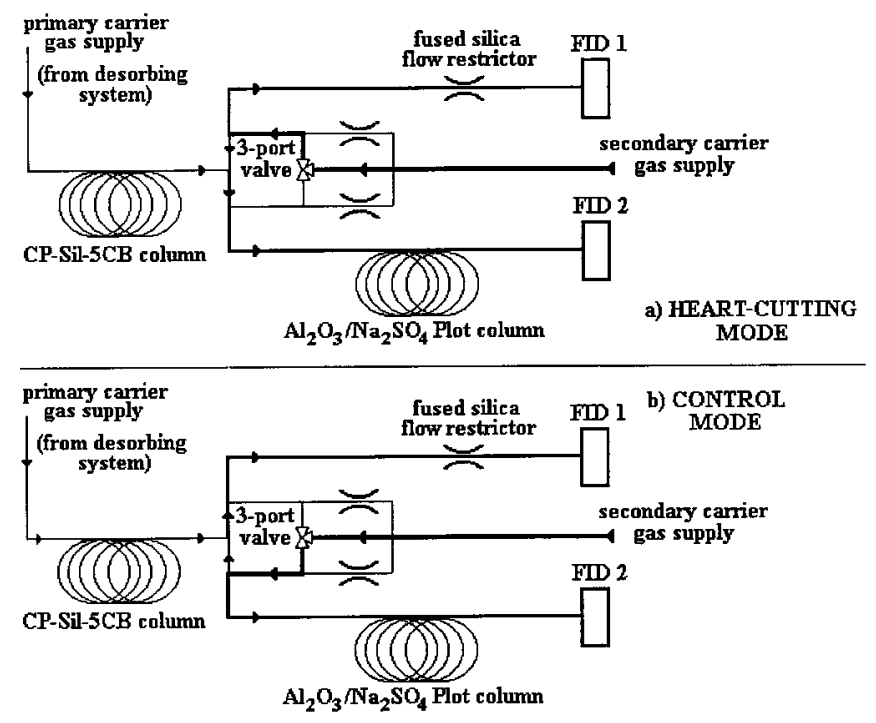

Figure 2. Flow diagram describing the column switch.

Table I. Chromatographic conditions for the analysis of individual NMHC in the air.

Perkin Elmer Autosystem GC oven

: $45^{\circ} \mathrm{C}$ isothermal for 10 minutes

: $7.5^{\circ} \mathrm{C} / \mathrm{min}$ to $170{ }^{\circ} \mathrm{C}$

: $15^{\circ} \mathrm{C} / \mathrm{min}$ to $200{ }^{\circ} \mathrm{C}$

: $200{ }^{\circ} \mathrm{C}$ isothermal for 10 minutes

carrier gas

: Helium: primary supply at 45 psi secondary supply at $22 \mathrm{psi}$

switch time

: 11 minutes

detection

: dual FID at $250{ }^{\circ} \mathrm{C}$ 
The oven temperature program combined with the switch time set at $11 \mathrm{~min}$ give an excellent resolution for nearly all components as represented in figure 3 , for a 31 compound standard gas mixture (in the $\mathrm{C}_{2}-\mathrm{C}_{9}$ range).

The analysis is completed in less than 30 minutes and only one coelution $(m-+p$-xylene $)$ is noticeable among these 31 compounds. Additional qualitative experiments have been carried out in the same analytical conditions with 49 other hydrocarbons (i.e. for an 80 component mixture in the $\mathrm{C}_{2}-\mathrm{C}_{12}$ range) and have shown only four more coelutions.

\section{Monitoring of individual NMHC in urban air}

The analytical facility described above has now been used for more than two years for different measurement experiments of the atmospheric concentrations of NMHC in urban areas.

\section{Target monitored compounds}

For the moment, neither a regulation text nor even international scientific unanimity exists for the definition of a representative list of compounds to be measured in urban areas. So, we have decided to follow during our air monitoring experiments the concentrations of a 31 hydrocarbons list recommended by a CEC working group of experts [13]. These compounds, presented in Table II, were defined as of the
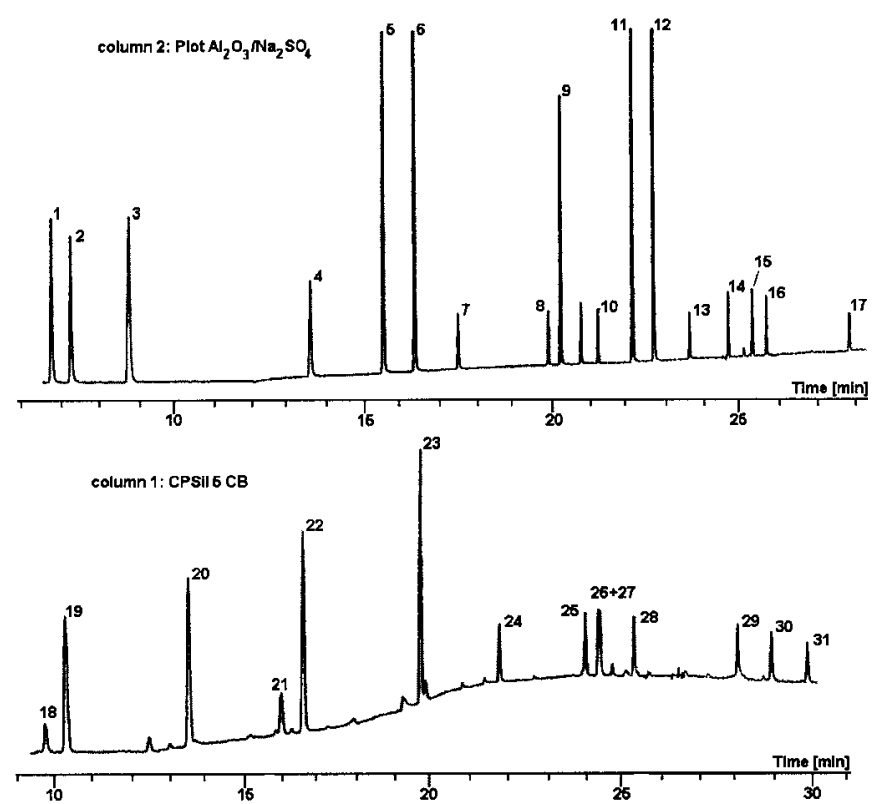

Figure 3. Separation of a C2 - C9 hydrocarbon standard gas mixture using heart-cutting chromatography. ethane: 1, ethene: 2, propane: 3 , propene: 4 , i-butane: 5 , n-butane: 6 , acetylene: 7, trans-2-butene: 8, 1-butene: 9, cis-2-butene: 10, i-pentane: 11, n-pentane: 12, 1,3-butadiene: 13, trans-2-pentene: 14, 1-pentene: 15, cis-2-pentene: 16, isoprene: 17, 1-hexene: 18, $n$-hexane: 19, benzene: 20, i-octane: 21, n-heptane: 22, toluene: 23, n-octane: 24, ethylbenzene: $25, m$-xylene: 26, p-xylene: 27, o-xylene: 28, 1,3,5-trimethylbenzene: 29, 1,2,4-trimethylbenzene: 30, 1,2,3-trimethylbenzene: 31 .
Table II. Individual non-methane hydrocarbons measured during our air monitoring studies.

\begin{tabular}{|c|c|c|c|c|c|}
\hline 1 & ethane & 12 & $n$-pentane & 23 & toluene \\
\hline 2 & ethene & 13 & 1,3-butadiene & 24 & $n$-octane \\
\hline 3 & propane & 14 & trans-2-pentene & 25 & ethylbenzene \\
\hline 4 & propene & 15 & 1-pentene & 26 & $m$-xylene \\
\hline 5 & i-butane & 16 & cis-2-pentene & 27 & $p$-xylene \\
\hline 6 & $n$-butane & 17 & isoprene & 28 & o-xylene \\
\hline 7 & acetylene & 18 & 1-hexene & 29 & $\begin{array}{l}\text { 1,3,5-trimethyl- } \\
\text { benzene }\end{array}$ \\
\hline & trans-2-butene & 19 & $n$-hexane & 30 & $\begin{array}{l}\text { 1,2,4-trimethyl- } \\
\text { benzene }\end{array}$ \\
\hline 9 & 1-butene & 20 & benzene & 31 & $\begin{array}{l}\text { 1,2,3-trimethyl- } \\
\text { benzene }\end{array}$ \\
\hline 10 & cis-2-butene & 21 & i-octane & & \\
\hline 11 & $i$-pentane & 22 & $n$-heptane & & \\
\hline
\end{tabular}

highest priority considering criteria of reactivity, emission rates, and abundances in urban atmospheres as well as in the free troposphere.

\section{Experimental conditions}

Our first field NMHC monitoring experimentation was held from May 1995 to September 1996, that is to say a 17 month period, in the town of Douai, in northern France. The sampling site was located at "L'École des Mines" which can be considered as an urban site. Practically, the sampling location was set at about $200 \mathrm{~m}$ from a main double track way leading to the city centre, submitted to a high density traffic (maximum of 4000 vehicles per hour) influenced by several traffic lights. Sampling was performed during 30 minutes every hour. Air samples of $600 \mathrm{~mL}$ were taken, which gave, in our analytical conditions detection limits better than $0.05 \mathrm{ppbv}$ for all the quantified components.

Calibration was carried out using a standard gas mixture containing the 31 target compounds in the ppbv range, and also by dilution of a COFRAC certified propane standard at $1.022 \mathrm{ppmv} \pm 1.17 \%$, both supplied by Air Liquide. Calibration coefficients for all components were calculated from the experimental one of propane, considering their theoretical response factors relative to carbon atom numbers [14]. Specific studies showed that differences between theoretical and experimental response factors were less than $10 \%$ for all quantified components. Weekly calibration was performed in order to follow the evolution of the response factors. At the end of the 17 months, calibration coefficients had changed by less than $10 \%$ in comparison with their initial values, sign of a very good stability of the response of the analyser.

During all the course of the experiment, the different monitoring operations (sampling, injection, analysis, quantification, data treatment...) were automatically performed. In particular, peak identification was achieved from retention times relative to the ones of judiciously chosen reference peaks. The correct assignation of the peaks was checked for all the chromatograms with the help of time retention con- 


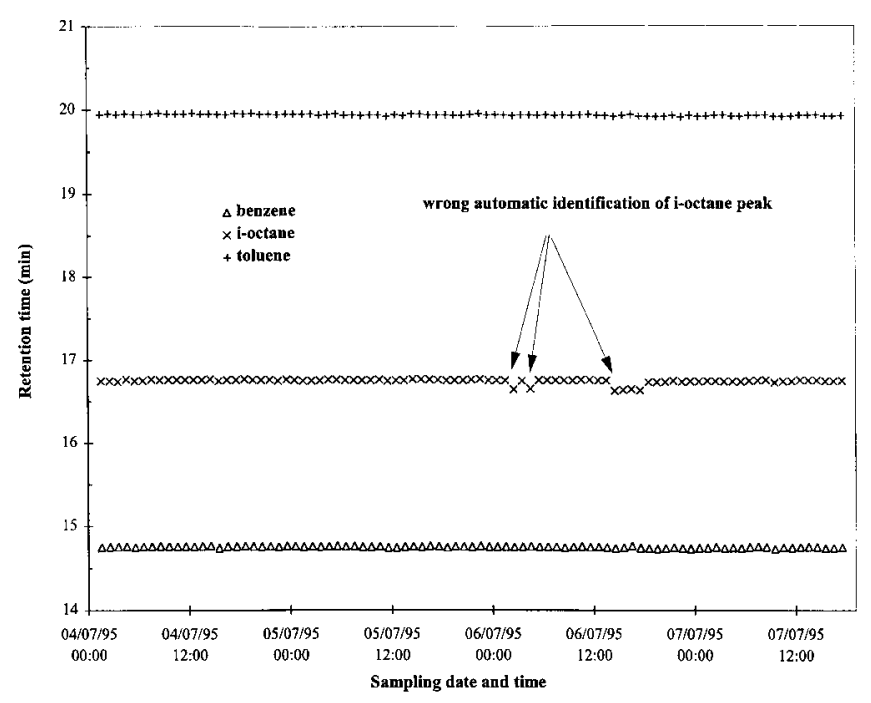

Figure 4. Example of time retention control chart used for checking peak identification.

trol charts. An example of such a graph is given in figure 4 . Any disruption in the normally flat curve representing peak retention times peak versus sampling time can be seen as a likely misidentification. Then the identification was verified, and eventually manually corrected, by the examination of the chromatogram. Identification mistake rates have been calculated over the 17 months duration of the experiment. While more than 10000 samples had been analysed, these rates were less than $2 \%$ for all but 6 of the 31 compounds studied. Larger numbers of mistakes (up to 5\%) were observed for compounds (isoprene, $n$-hexane, 1 -hexene, $n$ octane, $i$-octane and 1,2,4-trimethylbenzene) showing both low atmospheric concentration, and incomplete peak resolution, for which automatic identification was trickier.

\section{Atmospheric concentrations of NMHC in urban area}

At the end of the monitoring experiment, a concentration data base has been created, whose exploitation, in combination with additional information such as meteorological parameters, traffic counting, emission inventories..., can allow to draw very accurate pictures of the spatial and temporal variations of individual NMHC in air for the sampling site considered [15]. It is not the scope of this paper to present such a study and only some examples of our observations will be given here as an illustration of the utility of long term monitoring data for the characterisation of individual NMHC atmospheric behaviours.

Air concentrations of pollutants in urban areas are the result of a dynamic balance between source strengths, dilution processes and physico-chemical removal mechanisms taking place at the observation site. Then the concentration of any pollutant, for instance non-methane hydrocarbons, is subjected to wide variations as a consequence of modifications in the relative influences exerted by these parameters. A first example of the variety observed in the air levels of individual NMHC is shown in table III where the ranges of hourly concentrations measured for the 31 quantified compounds during the monitoring period are presented. The
Table III. Ranges of hourly concentrations measured for the 31 hydrocarbons quantified over the monitoring period.

\begin{tabular}{|c|c|c|c|}
\hline Compound & $\begin{array}{l}\text { Mean } \\
\text { (ppbv) }\end{array}$ & $\begin{array}{l}\text { Minimum } \\
\text { (ppbv) }\end{array}$ & $\begin{array}{c}\text { Maximum } \\
\text { (ppbv) }\end{array}$ \\
\hline ethane & 3.91 & 0.38 & 30 \\
\hline ethene & 3.01 & 0.09 & 155 \\
\hline propane & 2.74 & 0.10 & 370 \\
\hline$n$-butane & 2.61 & 0.11 & 860 \\
\hline acetylene & 2.36 & 0.10 & 350 \\
\hline toluene & 1.68 & 0.11 & 95 \\
\hline$i$-pentane & 1.61 & 0.10 & 81 \\
\hline$m-+p$-xylene & 0.95 & 0.07 & 77 \\
\hline$i$-butane & 0.92 & 0.03 & 124 \\
\hline benzene & 0.91 & 0.10 & 26 \\
\hline propene & 0.78 & 0.04 & 25 \\
\hline$n$-pentane & 0.64 & 0.04 & 20 \\
\hline ethylbenzene & 0.41 & 0.03 & 22 \\
\hline o-xylene & 0.36 & 0.03 & 29 \\
\hline $\begin{array}{l}\text { 1,2,4-trimethyl- } \\
\text { benzene }\end{array}$ & 0.32 & $<0.01$ & 33 \\
\hline n-hexane & 0.31 & $<0.01$ & 69 \\
\hline $\begin{array}{l}\text { 1,2,3-trimethyl- } \\
\text { benzene }\end{array}$ & 0.18 & $<0.02$ & 12.6 \\
\hline 1-butene & 0.17 & $<0.01$ & 6.3 \\
\hline 1,3-butadiene & 0.16 & $<0.02$ & 8.0 \\
\hline trans-2-butene & 0.15 & $<0.03$ & 8.1 \\
\hline cis-2-butene & 0.13 & $<0.01$ & 14.2 \\
\hline$n$-heptane & 0.13 & $<0.01$ & 11.1 \\
\hline $\begin{array}{l}\text { 1,3,5-trimethyl- } \\
\text { benzene }\end{array}$ & 0.11 & $<0.01$ & 14.0 \\
\hline trans-2-pentene & 0.10 & $<0.01$ & 6.5 \\
\hline isoprene & 0.10 & $<0.02$ & 7.5 \\
\hline n-octane & 0.07 & $<0.01$ & 6.6 \\
\hline 1-pentene & 0.06 & $<0.01$ & 3.9 \\
\hline 1-hexene & 0.06 & $<0.01$ & 4.1 \\
\hline i-octane & 0.06 & $<0.01$ & 1.8 \\
\hline cis-2-pentene & 0.05 & $<0.01$ & 3.9 \\
\hline
\end{tabular}

mean, the lowest and highest hourly values recorded for each hydrocarbon are given following relative abundance decreasing order.

Significant differences appear between mean hourly concentrations of compounds, reaching nearly two orders of magnitude between the most and least abundant ones. This classification reflects the global partition among weakly reactive, highly emitted compounds and quickly chemically degraded, low emission ones. Another interesting element given by table III is the range of variability of hourly levels of each compound. Depending on the species, the difference between minimum and maximum values can 
attain a factor of about 10000 (for $n$-butane) and is beyond a factor 100 for most of the compounds. This difference indicates for each hydrocarbon to what degree the emission and atmospheric dispersion extreme characteristics can affect the measured levels around the sampling site.

A more detailed illustration of the variety of NMHC behaviour in urban air can be seen considering their temporal variations at different time scales. In figures 5, 6 and 7, respectively the hourly, daily and monthly evolutions of concentrations of 4 compounds presenting typical patterns: ethane, 1,3-butadiene, isoprene and benzene, are shown.

In urban areas, benzene and 1,3-butadiene come from human activities, mainly from road transport, while ethane and isoprene have both anthropogenic and natural origins,
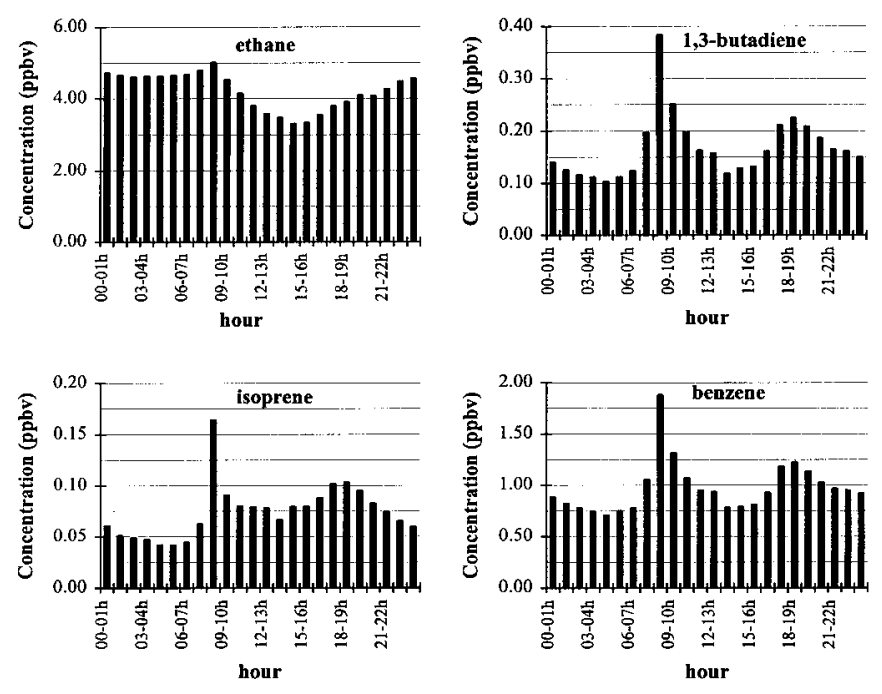

Figure 5. Hourly variations of the annual mean concentrations (from Sept. 95 to Aug. 96) of 4 hydrocarbons measured at "I'École des Mines de Douai” urban sampling site.

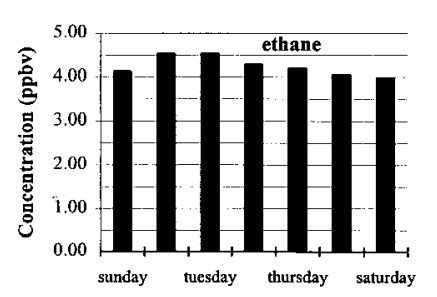

Day

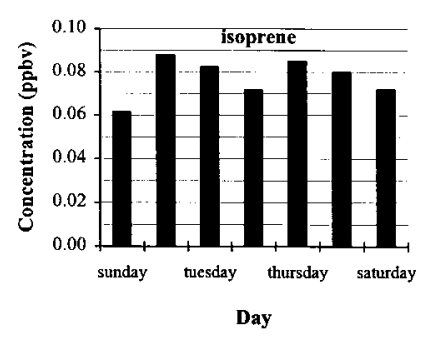

Figure 6. Daily variations of the annual mean concentrations (from Sept. 95 to Aug. 96) of 4 hydrocarbons measured at "I'École des Mines de Douai" urban sampling site. the latter being the preponderant hydrocarbon emitted from biogenic sources. Furthermore, isoprene and 1,3-butadiene are strongly reactive and are then removed from the atmosphere in a few hours. On the contrary, ethane and benzene have longer atmospheric lifetimes (more than several days) and may be transported fairly far from their sources.

The short-term influences of the strength of emission and meteorological parameters on the measured concentrations of the 4 hydrocarbons are shown in figure 5. A typical diurnal two peaks pattern (one in the morning at $7 \mathrm{~h}-10 \mathrm{~h}$ and one weaker in the evening between $17 \mathrm{~h}$ and $20 \mathrm{~h}$ ), corresponding to the traffic rush hours, is seen for the 3 less volatile compounds. The hourly profile for ethane is relatively different with high values at night that decrease during the day. This evolution is associated with the diurnal variation of the efficiency of the vertical dispersion linked to the rise of wind and mixing height during the day. This meteorological factor also explains the weaker concentration peak seen in the evening for the other 3 hydrocarbons.

The role of the source strength is as well observed from figure 6 where the evolution of daily mean concentration during the week are presented. All compounds show lower levels on weekend days, corresponding to the decrease in the urban road traffic.

The long-term monthly evolutions of the concentrations of the 4 hydrocarbons are given in figure 7 . All components but isoprene present maximum concentration during the autumn and winter months. This behaviour is generally associated with worse dispersion conditions and less photochemical activity during these periods. On the contrary, isoprene shows a maximum concentration during the summer. Although its chemical reactivity is extremely high, the summer increase of the concentration of this compound is the result of the intense biogenic activity taking place at this time.

This study shows that multidimensional capillary gas chromatography is a very suitable method for the analysis of individual NMHC in air, that can be used in particular for
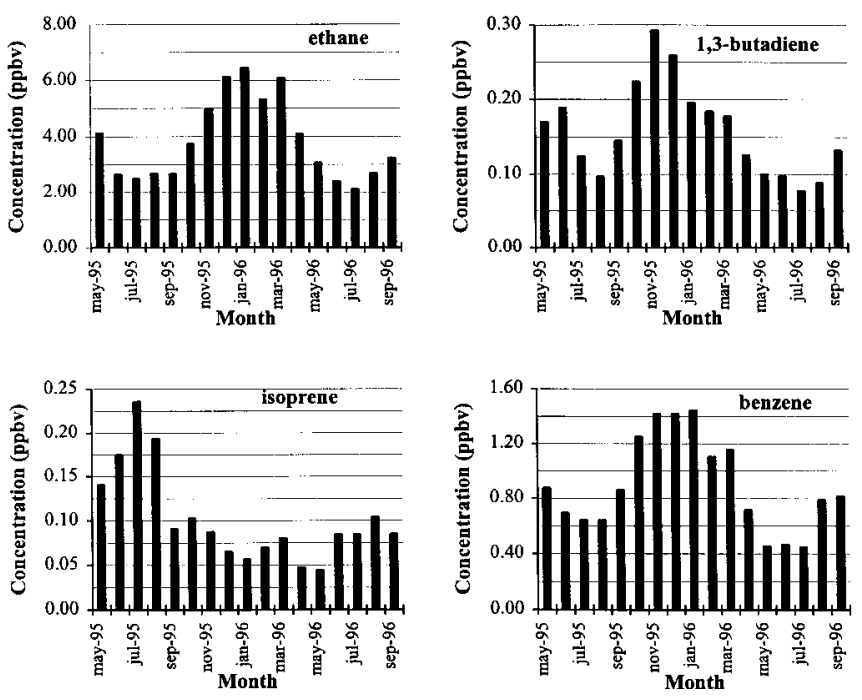

Figure 7. Seasonal variations of the monthly mean concentrations of 4 hydrocarbons measured at "I'École des Mines de Douai" urban sampling site. 
monitoring applications where high periodicity measurements are necessary. In this way, concentration data base can be set up, and the short- and long-term concentration variability be analysed and exploited for the population exposure assessment and simulation model validation.

\section{Acknowledgments}

The authors wish to thank the French Ministry of Environment and the French Agency of Environment and Energy (ADEME) for their financial support to this work. We are also grateful to Mr Leonardis for his technical assistance and to Mrs Coquelle for her valuable comments on this paper.

\section{References}

1. Ciccioli, P. In: Volatile organic compounds in the environment, Bloemen, H. J. Th.; Burn, J. Eds., Blackie Academic \& Professional, London, 1993; pp 92-174.

2. Woolfenden, E. A. In: Quality assurance in environmental monitoring, Subramanian, G. Ed., VCH, Weinheim, 1995; pp 133-191.
3. Boudries, H.; Toupance, G.; Dutot, A. L. Atm. Env. 1994, 28, 1095-1112.

4. Field, R. A.; Goldstone, M. E.; Lester, J. N.; Perry, R. Env. Tech. 1994, 15, 931-944.

5. Yokouchi, Y.; Ambe, Y.; Maeda, T. Anal. Sci. 1986, 2, 571575.

6. Moschonas, N.; Glavas, S. Atm. Env. 1996, 30, 2769-2772.

7. Lay, J. Y. K.; Matisova, E.; He, D.; Singer, E.; Niki, H. J. Chromatogr. 1993, 643, 77-90.

8. Jonhson, G.; Marmonier, C.; Garrabé, G. Spectra 2000 1988, $16,23-35$.

9. Witier, P. In: Manuel pratique de chromatographie en phase gazeuse: $4^{\text {ème }}$ édition, Tranchant, J. Ed., Masson, Paris, 1995; pp 587-603.

10. Mosandl, A. Analusis 1997, 25, M31-M38.

11. Rudlein, N.; Geiger, W.; Pelz, N.; Scherrbacher, H. J. SAE Technical Paper Series, 1994, Paper n940827, 31-44.

12. Mc Clenny, W. A. In: Volatile organic compounds in the environment, Bloemen, H. J. Th.; Burn, J. Eds., Blackie Academic \& Professional, London, 1993; pp 237-267.

13. Kotzias, D.; Hjorth, J. Pollution Atmosphérique, 1991, nº spécial juillet, 209-216.

14. Tranchant, J. In: Manuel pratique de chromatographie en phase gazeuse: $4^{\mathrm{ème}}$ édition, Tranchant, J. Ed., Masson, Paris, 1995; pp 452-492.

15. Derwent, R. G.; Middleton, D. R.; Field, R. A.; Goldstone, M. E.; Lester, J. N.; Perry, R. Atm. Env. 1995, 29, 923-946. 